\title{
Arterial Thromboembolism, CTCAE
}

National Cancer Institute

\section{Source}

National Cancer Institute. Arterial Thromboembolism, CT CAE. NCI Thesaurus. Code C143249.

A disorder characterized by occlusion of an arterial vessel by a blood clot that develops in an artery. 